\title{
Childhood rosacea
}

\section{Lidia E. Bernal ${ }^{1 *}$, Ana P. Zarco², Pablo Campos ${ }^{3}$ and Roberto Arenas ${ }^{4}$}

${ }^{1}$ División de Dermatología, Hospital General Dr. Manuel Gea González, Mexico City; ${ }^{2}$ Centro Médico ABC, Mexico City; ${ }^{3}$ División de Dermatớogía, Hospital Aranda de la Parra General Hospital, Guanajuato; ${ }^{4}$ División de Dermatología y Micología, Hospital General Dr. Manuel Gea González, Mexico City. Mexico

\begin{abstract}
Background: Rosacea is a chronic inflammatory skin condition that usually occurs in adults and rarely has been reported in children, although both subtypes share the same clinical characteristics. Case report: A 10-year-old female presented dermostosis on the face, affecting cheeks and nose, characterized by erythema, papules, pustules, scars of two years of evolution, as well as bilateral conjunctivitis, blepharitis and corneal opacity. She referred recurrent exacerbations and partial remission of cutaneous lesions and ocular symptoms related to sun exposure. She responded dramatically to systemic and topical antibiotics. Conclusions: Childhood rosacea should be distinguished from other most common erythematous tàcial disorders, such as acne, granulomatous perioral dermatitis, and sarcoidosis. The distribution of papulopustular facial lesions together with the presence of telangiectasia, flushing and the ocular findings allow the differentiation of rosacea from other
\end{abstract} facial eruptions.

Key words: Acne. Rosacea. Bacterial infection. Infestations. Inflammatory disorders.

\section{Rosácea infantil}

\section{Resumen}

Introducción: La rosácea es una enfermedad inflamatoria crónica de la piel que generalmente afecta adultos. Rara vez se ha reportado en niños, aunque ambos subtipos comparten las mismas características clínicas. Caso clínico: Se reporta el caso de una paciente de 10 años de edad con dermostosis que afecta las mejillas y la nariz. La lesión está caracterizada por eritema, pápulas, pústulas, cicatrices de 2 años de evolución, así como conjuntivitis bilateral, blefaritis y opacidad corneal. Presentó exacerbaciones recurrentes de las lesiones cutáneas y síntomas oculares relacionados con la exposición solar. La paciente respondió muy bien a la terapia con antibióticos tópicos y sistémicos. Conclusiones: La rosácea infantil debe distinguirse de otros trastornos faciales eritematosos con mayor frecuencia, como el acné, la dermatitis perioral granulömatosa y la sarcoidosis. La distribución de las lesiones faciales papulopustulares junto con la presencia de telangiectásias, rubor y los hallazgos oculares permiten la diferenciación de la rosácea de otras erupciones faciales.

Palabras clave: Acné. Rosácea. Infección bacteriana. Infestación. Trastornos inflamatorios.

2444-3409/๑ 2018. Hospital Infantil de México Federico Gómez, published by Permanyer México SA de CV, all rights reserved.
Available online: $14-01-2020$ Bol Med Hosp Infant Mex. 2019; 76:89-92 www.bmhim.com 


\section{Introduction}

Rosacea is a chronic inflammatory skin disease that usually affects adults. Although it has rarely been reported in children, both subtypes of the disease share the same clinical characteristics, differing only from the phymatous form. The case of a female patient with ocular and cutaneous rosacea who responded dramatically to systemic and topical antibiotics is reported.

\section{Clinical case}

A 10-year-old female patient attended a medical service with dermostosis affecting the cheeks and the back of the nose. The lesion was characterized by erythema, papules, pustules, scars of 2 years of evolution (Fig. 1), as well as bilateral conjunctivitis, blepharitis, and corneal opacity (Fig. 2). The patient presented recurrent exacerbations of skin lesions and eye symptoms related to sun exposure. Physical examination and laboratory tests such as blood count and antinuclear antibodies were normal and negative, respectively.

A skin biopsy was performed, in which a stratum corneum with parakeratosis and spongiosis was observed, as well as a perivascular and perifollicular infiltrate of granulomatous appearance, composed of lymphocytes, histiocytes and plasma cells (Fig. 3).

With all the clinical and histopathological data, a definitive diagnosis of infantile rosacea was made and treatment with erythromycin $30 \mathrm{mg} / \mathrm{kg} /$ day, topical metronidazole, and $2 \%$ selenium disulfide in shampoo was indicated.

Reduced inflammatory lesions, decreased facial erythema and telangiectasia were observed (Fig. 4A). The ocular symptoms presented less response to the treatment and persisted for a month before observing improvement (Fig. 4B).

\section{Discussion}

Infantile rosacea is a chronic and recurrent inflammatory dermatosis not frequently reported because of its clinical similarity with other facial erythematous diseases, especially acne. ${ }^{1,2}$ Rosacea usually involves the central region of the face, which presents erythema, telangiectasia, and inflammatory skin lesions. ${ }^{3}$

Rosacea is more prevalent in patients older than 30 years. Its prevalence in children is unknown because most studies are carried out in adult populations. ${ }^{4}$ However, samples have been made with more than 60,000 cases, of which $10 \%$ of the patients were under 20 years of age. ${ }^{5}$

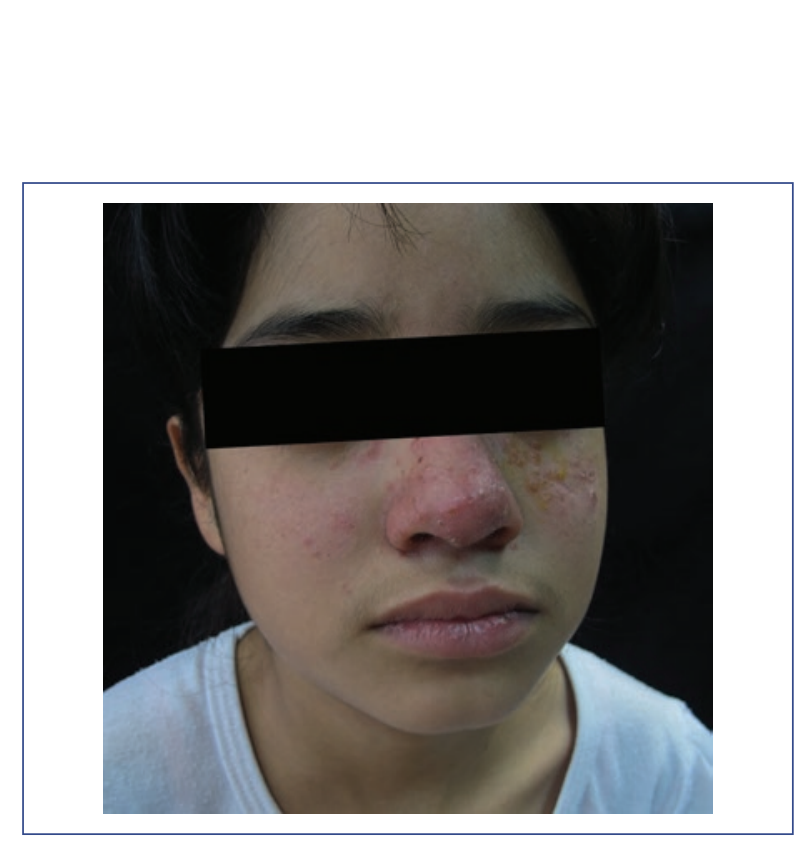

Figure 1. Infantile rosacea with the presence of facial erythema, papules, crusts, and telangiectasias.

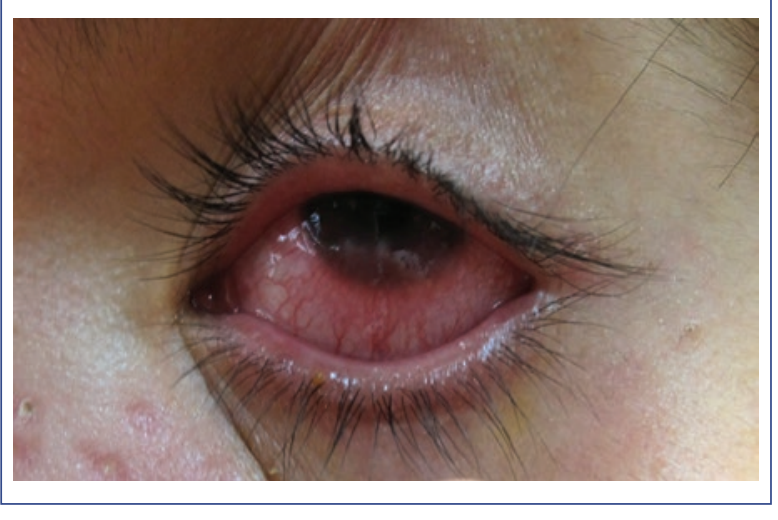

Figure 2. Ocular and palpebral involvement, presence of hyperemia associated with erythema of the limbus, corneal neovascularization, and telangiectasias.
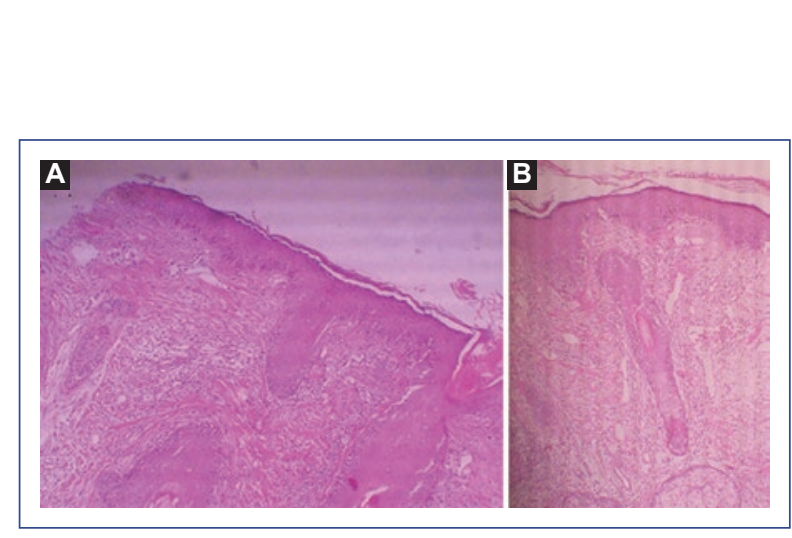

Figure 3. A: Granulomatous infiltrate with plasma cells $\bar{s}$ and neutrophils (hematoxylin-eosin staining, HE 40x); dilated capillaries in the dermis with a lymphohistiocytic infiltpate predominantly centered in the hair follicles (HE 40X). B: Granuloma with histiocytes, giant multinucleated cells, and Demodex folliculorum within the follicle (HE 40x)? 


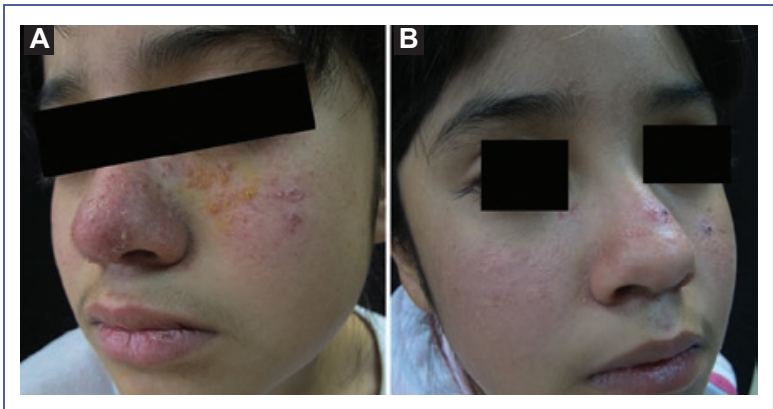

Figure 4. A: Granulomatous rosacea associated with severe ocular rosacea (keratoconjunctivitis). B: After treatment, a significant improvement is observed.

Table 1. Criteria of infantile rosacea ${ }^{8}$

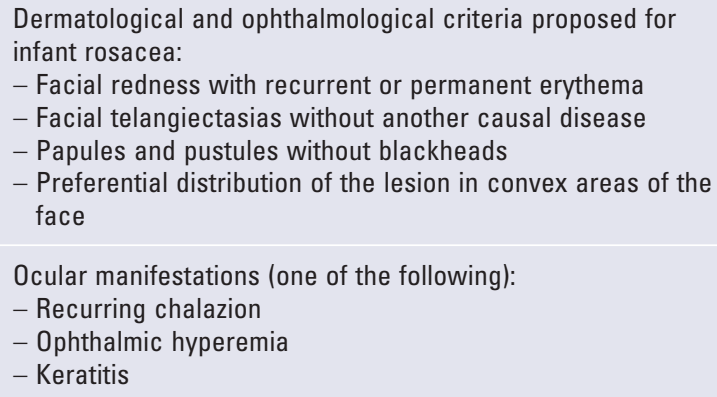

Ocular rosacea is present with chronic bilateral blepharitis and dysfunction of Meibomian glands. The slit-lamp examination shows marginal telangiectasias of the eyelid and inflammation data. Patients frequently develop dry eye and recurrent chalazion, accompanied by burning sensation, photophobia, and foreign body sensation. ${ }^{6,7}$

As there are no diagnostic criteria for childhood rosacea, some authors have suggested the application of clinical criteria used in adults. Although only one criterion is sufficient to make the diagnosis in adults, it is recommended to meet at least two criteria in case of childhood rosacea (Table 1). ${ }^{8}$

\section{Etiopathogenesis}

It is believed that rosacea is an inflammatory disease without a definitive etiology. However, several factors are involved, such as vasomotor instability with an increase in the number of blood vessels and blood flow, which are responsible for the permanent and transient redness. ${ }^{9}$ It also represents a type IV hypersensitivity reaction, with a possible relationship with ultraviolet radiation that acts as a trigger to activate free radicals, fibroblast growth factors, and vascular endothelial growth factor (VEGF). All of them contribute to the clinical manifestations of rosacea and the degeneration of the dermal matrix and cause accumulation of sevium and inflammatory mediators. It has been shown that spicy foods, alcohol, and hot drinks activate the transient potential receptor V1 (TRPV1), which has been implicated in redness and sensitivity in the skin. $9,10$.

As part of the innate immune response, some antimicrobial peptides have demonstrated broad-spectrum antimicrobial activity against bacteria, viruses, and fungi. Cathelicidins and beta-defensins, particularly cathelicidin LL-37 peptide and the proteolytical forms of: Teukocytes such as lymphocytes and polymorphonuclear cells, interact with endothelial cells, stimulate angioḡenesis, and modulate VEGF expression, which can allso be exacerbated by alcohol and coffee due to its vâsodilatory effects. ${ }^{11}$

\section{Treatment}

The treatment for rosacea in children is similar to that for adults, but erythromycin is preferred to tetracyclines since the latter are contraindicated in children under 8 years of age. A combination of systemic antibiotics and topical treatment can lead to a substantial reduction of inflammatory lesions and decrease the erythema and the size of the telangiectatic vessels. ${ }^{12}$

Tetracycline and doxycycline are commonly used in ocular rosacea since they have been shown to reduce inflammatory lesions and decrease the expression of metalloproteinases that change the serine protease KLK5 to its active form. Tetracyclines also accumullate in sebum and decrease bacterial lipase, which contributes to downregulation of inflammatory cytokines and neutrophil infiltration. ${ }^{13}$

Oral tetracycline is contraindicated for ocular rosacea in patients under 8 years of age. One alternative is@oral erythromycin, which shows a beneficial effect on organisms that produce infantile blepharokeratitis. ${ }^{13}$

Topical metronidazole gel (0.75-1.0\%) and ivermectin cream twice a day are useful in the treatment of rogsacea skin manifestations due to their ability to decrease the generation of reactive oxygen species and demodicosis, which have been postulated within the physiopathology of rosacea. ${ }^{14,15}$

Another treatment option is the use of technology, such as laser and high-energy light sources known as intense pulsed light. The latter is a non-coherent, polychromatic type of light, which favors the destruction of pigments such as melanin and oxyhemoglobin, and has shown 
marked improvement in both erythema and telangiectasia due to the wavelengths used, and also induce neocollagen and remodeling of dermal collagen. ${ }^{16}$

\section{Differential diagnosis}

Due to its similarity with other inflammatory diseases, the primary differential diagnoses are, firstly, acne vulgaris, due to the presence of papules and pustules. Howev$\mathrm{er}$, characteristically, there are no blackheads in rosacea. Secondly, the facial pyoderma, whose evolution is abrupt and is characterized by the presence of violaceous erythema with purulent nodulocystic lesions and abundant pustules. Also, perioral dermatitis, which shows perioral, perinasal, and periocular involvement with small monomorphic erythematous papules of translucent, isolated or confluent appearance, mostly associated with the use of topical steroids. Conversely, seborrheic dermatitis usually presents erythema in the center of the face with an oily-looking scale. Within connective tissue diseases, systemic lupus erythematosus, as well as dermatomyositis, should be considered in the differential diagnosis of rosacea due to the presence of persistent facial erythema with more significant association to systemic and musculoskeletal alterations. ${ }^{17}$ Granulosis rubra nasi, Haber's syndrome, facial tinea, luminous polymorphous eruption, and sarcoidosis, among others, should also be ruled out.

In conclusion, infantile rosacea should be distinguished from other erythematous facial disorders, mainly acne, perioral granulomatous dermatitis, and sarcoidosis. The disease in the pediatric population resembles the disease in adults, except for chronic changes, such as rhinophyma, which occurs in adults if the disease persists. It is essential to look for the relation of a previous antecedent of idiopathic aseptic facial granuloma, which is a granulomatous dermatological process characteristic of the pediatric age characterized by the presence of an acquired inflammatory nodule of long evolution in the facial skin, without pain or local heat, which may progress to infantile rosacea, associated with ocular symptoms. ${ }^{17-19}$

The distribution of the papulopustular facial lesions and the presence of telangiectasias, flushing, and ocular findings allow the differentiation of rosacea from other facial eruptions, and even more, with criteria for the diagnosis of infantile rosacea.

\section{Ethical disclosures}

Protection of human and animal subjects. The authors declare that no experiments were performed on humans or animals for this study.
Confidentiality of data. The authors declare that they have followed the protocols of their work center on the publication of patient data.

Right to privacy and informed consent. The authors have obtained the written informed consent of the patients or subjects mentioned in the article. Theocorresponding author is in possession of this document.

\section{Conflicts of interest}

The authors declare that they have no conflicts of interest.

\section{Funding}

None.

\section{Acknowledgments}

We thank all the authors for their motivation and effort towards pediatric dermatology.

\section{References}

1. Bamfort JT, Gessert CE, Renier CM, Jackson MM, Laabs SB, Dahl MV, et al Childhood style and adult rosacea. J Am Acad Dermatol. 2006;55:95125.

2. Drolet B, Paller AS. Childhood rosacea. Pediatr Dermatol. 1992;922-6.

3. Wilkin J, Dahl M, Detmar M, Drake L, Liang MH, Odom R, et al. Standard grading system for rosacea: report of the National Rosacea Society Expert Committee on the classification and staging of rosacea. J Am Acad Dermatol. 2004;50:907-12.

4. Tan J, Berg M. Rosacea: current state of epidemiology. J Am Acad Dermatol. 2013;69:S27-35.

5. Spoendlin J, Voegel JJ, Jick SS, Meier CR. A study on the epidemiology of rosacea in the UK. Br J Dermatol. 2012;167:598-605.

6. Nazir SA, Murphy S, Siatkowski RM, Chodosh J, Siatkowski RL. Ocular rosacea in childhood. Am J Ophthalmol. 2004;137:138-4.

7. Prey S, Ezzedine K, Mazereeuw-Hautier J, Eschard C, Barbarot S, Boralevi $\mathrm{F}$, et al. IFAG and childhood rosacea: a possible link? Rediatr Dermatol. 2013;30:429-32.

8. Chamaillard M, Mortemousque B, Boralevi F, Marques da Costa C, Aitali $F$, Taïeb A, et al. Cutaneous and ocular signs of childhood rosacea. Arch Dermatol. 2008;144:167-71.

9. Çetinkaya AG, Akova YA. Pediatric ocular acne rosacea: long-term treatment with systemic antibiotics. Am J Ophthalmol. 2006;142:816-21.

10. Schwab VD, Sulk M, Seeliger S, Nowak P, Aubert J, Mess C, et al. Neurovascular and neuroimmune aspects in the pathophysiology of rosacea. J Investig Dermatol Symp Proc. 2011;15:53-62.

11. Two AM, Wu W, Gallo RL, Hata TR. Rosacea: part I. Introduction categorization, histology, pathogenesis, and risk factors. J Am Acad Dermatol. 2015;72:749-58.

12. Weinkle AP, Doktor V, Emer J. Update on the management of rosâcea. Clin Cosmet Investig Dermatol. 2015;8:159-77.

13. Two AM, Wu W, Gallo RL, Hata TR. Rosacea: part II. Topical and systemic therapies in the treatment of rosacea. J Am Acad Dermatol. 2015;72:761-70.

14. Park SY, Kwon HH, Min S, Yoon JY, Suh DH. Epidemiology and risk factors of childhood acne in Korea: a cross-sectional community-based study. Clin Exp Dermatol. 2015;40:844-50.

15. Jarmuda S, O'Reilly N, Zaba R, Jakubowicz O, Szkaradkiewicz A, Kavanagh K. Potential role of Demodex mites and bacteria in the induction of rosacea. J Med Microbiol. 2012;61:1504-10.

16. Lim HS, Lee SC, Won YH, Lee JB. The efficacy of intense pulsed light for treating erythematotelangiectatic rosacea is related to severity and age. Ann Dermatol. 2014;26:491-5.

17. Lacz NL, Schwartz RA. Rosacea in the pediatric population. Cutis. 2004 ; 74:99-103.

18. Zuber TJ. Rosacea. Prim Care. 2000;27:309-18.

19. Borok J, Holmes R, Dohil M. Idiopathic facial aseptic granuloma-adiagnostic challenge in pediatric dermatology. Pediatr Dermatol. 2018;35:490-3. 